\title{
Action of neuwiedase, a metalloproteinase isolated from Bothrops neuwiedi venom, on skeletal muscle: an ultrastructural and immunocytochemistry study
}

Baldo C (1), Ferreira MJ (2), Lopes DS (1), Izidoro LFM (3), Gomes AO (4), Ferro EAV (4), Hamaguchi A (5), Homsi-Brandeburgo MI (5), Rodrigues VM (5)

(1) Laboratory of Immunopathology, Butantan Institute, São Paulo, São Paulo State, Brazil; (2) Special Laboratory of Applied Toxinology, CAT/CEPID, Butantan Institute, São Paulo, São Paulo State, Brazil; (3) Integrated Sciences School of Pontal-Federal University of Uberlândia; (4) Institute of Biomedical Science, Federal University of Uberlândia, Uberlândia, Minas Gerais State, Brazil; (5) Institute of Genetics and Biochemistry, Federal University of Uberlândia, Uberlândia, Minas Gerais State, Brazil.

\begin{abstract}
The damaging effects of neuwiedase, a non-hemorrhagic snake venom metalloproteinase from P-I class, on gastrocnemius muscle are studied herein. Following neuwiedase injection, ultrastructural alterations were detected early showing disarrangement of skeletal muscle fibers (characterized by discontinuity of $Z$ lines), mitochondrial swelling, and disruption of plasma membrane and basal lamina. Degradation of skeletal muscle and the appearance of an amorphous substance, primarily composed of cellular debris, were noted after 24 hours. The presence of neuwiedase at the injection site (detected by immunocytochemistry) revealed highly specific labeling of myofibril components of damaged myocytes. In addition, proteolysis of muscle proteins assayed through myofibrils extracted from gastrocnemius muscle indicated that neuwiedase provoked degradation of myofibrils, especially myosin. These results suggest that skeletal muscle damage, induced by neuwiedase, is probably due to its proteolytic action on myofibrils, which are responsible for the maintenance of the cellular architecture.
\end{abstract}

Key words: skeletal muscle, neuwiedase, snake venom metalloproteinases, Bothrops neuwiedi.

\section{INTRODUCTION}

Envenoming induced by Bothrops snakes involves systemic toxic effects and striking alterations at the injection site, leading to variable degrees of local tissue damage (1). These local effects have been defined as pain, hemorrhage, edema, myonecrosis and inflammation. The snake venom metalloproteinases (SVMPs) have been considered as playing a crucial role in the development of the local venom-induced pathogenesis (2-4).

The SVMPs comprise an important class of zinc-dependent enzymes of varying molecular mass. These enzymes are part of the metzincins superfamily, a diverse and expansive group of zinc peptidases from both prokaryotes and eukaryotes $(5,6)$. SVMPs are synthesized as multidomain zymogen proteins and are grouped in classes and subclasses from P-I to P-III according to their domain organization (7). SVMPs from P-I class are composed in the mature form only of the catalytic domain and are generally fibrinogenolytic and weak hemorrhagic enzymes. The P-II SVMPs are synthesized with a metalloproteinase plus a disintegrin domain, but are frequently found in venoms as a processed form containing only a disintegrin domain, the classical disintegrins. SVMPs from P-III class are frequently potent hemorrhagins that consist of a catalytic domain followed by disintegrin-like and cysteine-rich domains, linked via the carboxy-terminal to the catalytic domain. P-I and P-III SVMPs are the most abundant group in viper venoms which conserve the catalytic domain in the mature form (7).

In 2000, Rodrigues et al. (8) described theisolation and biochemical characterization of a new P-I class SVMP $(22 \mathrm{kDa})$ from Bothrops neuwiedi venom, 
named neuwiedase. Neuwiedase is able to degrade fibrinogen, fibrin, type I collagen, fibronectin, and laminin. It is devoid of hemorrhagic activity on skin tests, but induces myotoxicity in mice models $(8,9)$. Recently, it was shown that neuwiedase induced an evident inflammatory infiltrate and an increase of matrix metalloproteinase-9 (MMP-9), interleukin-1 (IL-1), interleukin-6 (IL-6), interleukin-8 (IL-8), in the early periods after neuwiedase injection in the gastrocnemius muscle. The cytokine release was also evaluated in inflammatory and muscular cell culture and both murine peritoneal adherent cells (MAPCs) and mouse myoblast (C2C12) released proinflammatory cytokines after stimulus with neuwiedase (10).

In the present study, the skeletal muscle alterations induced by neuwiedase using transmission electron microscopy and immunocytochemistry are reported. This methodology can help to clarify the mechanism of action of this important class of venom toxin.

\section{MATERIALS AND METHODS}

\section{Toxins and Antibodies}

Neuwiedase was isolated from Bothrops neuwiedi venom according to Rodrigues et al. (8). Rabbit anti-neuwiedase polyclonal antibody was produced, as previously described (9).

\section{Ultrastructural and Immunocytochemistry Analysis}

Groups of three C57BL/6 mice (18-22 g) were injected intramuscularly in the gastrocnemius muscle with $50 \mu \mathrm{g}$ of neuwiedase dissolved in $50 \mu \mathrm{L}$ of phosphate buffered saline. The control group received only $50 \mu \mathrm{L}$ of PBS. At 1, 3, 6 and 24 hours post-injection, the animals were sacrificed by $\mathrm{CO}_{2}$ inhalation and the gastrocnemius muscle was dissected out, fixed and processed appropriately for either electron microscopy or immunocytochemistry. The ultrastructural analyses were performed after each post-injection time point and the tissues were fixed by immersion in $2.5 \%$ glutaraldehyde in $0.08 \mathrm{M}$ cacodylate buffer, $\mathrm{pH} 7.4$, for 24 hours, dehydrated in crescent ethanol series (50-100\%), and embedded in epon resin. Ultrathin sections of $60 \mathrm{~nm}$ were stained with lead citrate and uranyl acetate, and examined using a Zeiss EM $109^{\circ}$ electron microscope (Germany).

Immunocytochemistry was performed 15 minutes, 30 minutes, one hour and three hours after neuwiedase injection. The sections were dehydrated in ethanol and embedded in LR White ${ }^{\oplus}$ resin (Sigma Chemical Co., USA). Ultrathin sections were then placed on nickel grids and hydrated with Trisbuffered saline (TBS). The sections were then treated with $2 \%$ normal goat serum diluted in the same buffer, incubated overnight at $4^{\circ} \mathrm{C}$ with rabbit antineuwiedase serum, rinsed in TBS, and incubated with gold-conjugated anti-rabbit IgG (gold particle diameter $15 \mathrm{~nm}$; Sigma Chemical Co., USA), for one hour at $37^{\circ} \mathrm{C}$. The grids were finally stained with lead citrate and uranyl acetate and analyzed with an electron microscope. Negative controls were obtained by replacement of anti-neuwiedase serum by an irrelevant antibody (rabbit anti-Toxoplasma gondii). In addition, the muscle tissue injected only with PBS and incubated with anti-neuwiedase serum was used as a negative control.

\section{Phospholipase $A_{2}$ Activity}

The phospholipase activity of neuwiedase was determined upon egg-yolk emulsion, which contains phosphatidylcholine as substrate, according to De Haas et al. (11).

\section{Proteolysis of Muscle Proteins}

The myofibrils extraction was performed according to a method previously described (12). About $2.5 \mathrm{~g}$ of gastrocnemius muscle from normal male C57BL/6 mice were homogenized in three volumes of extraction buffer $(50 \mathrm{mM}$ Tris- $\mathrm{HCl}, \mathrm{pH}$ 6.8, $10 \mathrm{mM}$ EDTA, $0.05 \% \beta$-mercaptoethanol and $2 \mathrm{mM}$ of phenylmethylsulfonyl fluoride). After centrifugation $\left(1.500 \times \mathrm{g}, 20\right.$ minutes, $\left.4^{\circ} \mathrm{C}\right)$ the pellet was re-suspended in $40 \mathrm{~mL}$ of elution buffer (40 mM Tris-HCl, pH 7.35, 0.5 mM EDTA, 0.05\% $\beta$-mercaptoethanol), centrifuged (1.500 x g, 20 minutes, $4^{\circ} \mathrm{C}$ ) and the supernatant was discarded. The pellet was washed with $40 \mathrm{~mL}$ of $40 \mathrm{mM}$ Tris$\mathrm{HCl}, \mathrm{pH} 7.35$, containing $20 \mathrm{mMCaCl}_{2}$, centrifuged $\left(1.500 \mathrm{x} \mathrm{g}, 20\right.$ minutes, $\left.4^{\circ} \mathrm{C}\right)$, and the supernatant discarded. This washing procedure was repeated twice, and the protein concentration of an aliquot of the washed myofibrils was determined by the Bradford method (13). Degradation of muscle proteins was monitored by incubation of $5 \mu \mathrm{g}$ of neuwiedase with $100 \mu \mathrm{g}$ of myofibrils at different time points (5, 30 minutes, and 1, 3, 6, 24 hours) at $37^{\circ} \mathrm{C}$. The control reaction was incubated with PBS for 24 hours. The reaction was stopped with $25 \mu \mathrm{L}$ of $0.05 \mathrm{M}$ Tris- $\mathrm{HCl}$ buffer ( $\mathrm{pH}$ 8.8) containing $10 \%(\mathrm{v} / \mathrm{v})$ glycerol, $10 \%(\mathrm{v} / \mathrm{v}) \beta$-mercaptoethanol, 
$2 \%(\mathrm{v} / \mathrm{v})$ SDS, and $0.05 \%(\mathrm{w} / \mathrm{v})$ bromophenol blue. The samples were then analyzed by $13.5 \%(\mathrm{w} / \mathrm{v})$ SDS-PAGE according to Laemmli (14).

\section{Ethical Aspects}

The conduct and procedures involving animal experiments were approved by the Ethics Committee on Animal Experiments of Federal University of Uberlândia.

\section{RESULTS}

\section{Ultrastructural Alterations Induced by Neuwiedase in Gastrocnemius Muscle}

The morphological alterations induced by neuwiedase in gastrocnemius muscle were first analyzed by transmission electron microscopy. Analyses of samples injected with PBS showed organized myofibrils with typical $\mathrm{Z}$ lines and preserved mitochondria (Figure $1-\mathrm{A}$ ). After one hour of neuwiedase injection, the muscle fibers showed disorganized myofibrils and disruptions in the continuity of plasma membrane (Figure 1-B). At three hours, disorganization of myofibrils was verified, discontinuity of $Z$ lines was observed and inflammatory cells were present at the injection site (Figure $1-C$ ). At six hours, hypercontraction of myofilaments and mitochondrial swelling were also observed (Figure 1 - D). After 24 hours, some fibrils revealed an amorphous content and the characteristic myofibril pattern could no longer be distinguished. In addition, the integrity of the basal lamina and plasma membrane was affected. Some inflammatory cells were observed close to the damaged site, but erythrocytes were not detected in the interstitial space confirming the absence of hemorrhagic activity in the skeletal muscle injected with neuwiedase (Figure $1-\mathrm{E}$ ).

The possibility of any contamination of neuwiedase samples with myotoxic phospholipases $\mathrm{A}_{2}$, was ruled out using different approaches. First, the purity of neuwiedase samples was checked by SDSPAGE that showed only one band corresponding to the neuwiedase molecular weight. Neuwiedase samples were also tested for phospholipolytic activity on egg yolk lecithin, with negative results. Moreover, no immunological cross-reactivity was found by immunoblotting when neuwiedase was confronted with anti-myotoxin antibodies, produced in rabbits by immunization with BthTX-I, the prototype of myotoxic phospholipases $A_{2}$ isolated from B. jararacussu.

\section{Immunodetection of Neuwiedase on Muscle Tissue}

The aforementioned ultrastructural alterations were correlated with the presence of neuwiedase, at the lesion site. Earlier time points were chosen in order to detect the first events of muscle-toxin interaction. Muscular tissues injected only with PBS collected after 15 minutes (Figure 2 - A), 30 minutes (Figure $2-\mathrm{D}$ ), one hour (Figure $2-\mathrm{G}$ ) and three hours (Figure $2-\mathrm{J}$ ) were not labeled with anti-neuwiedase serum. The non-specific labeling of neuwiedase was also excluded by the incubation of neuwiedase-injected tissues with an irrelevant antibody (rabbit anti-Toxoplasma gondii) (Figure 2 - L). In contrast, clear labeling was observed in tissues injected with neuwiedase and incubated with anti-neuwiedase antibodies. Fifteen minutes after the toxin administration, colloidal gold label was observed in the endomysium (Figure $2-\mathrm{B}$ ), as well as inside the fiber, predominantly in the $\mathrm{Z}$ line (Figure $2-C$ ). At 30 minutes, the immunoreaction was detected mainly at the I-band (Figure $2-\mathrm{E}$ and $\mathrm{F}$, in cross-section). At one hour, the labeling occurred predominantly at the A-band (Figure 2 - $\mathrm{H}$ and I). At three hours, altered myofibrils were observed, and the colloidal gold label was detected in the myofilaments. Leukocyte infiltrate near the fiber was also noted (Figure $2-\mathrm{K}$ ).

\section{Proteolysis of Muscle Proteins}

In order to explore further effects of the toxin on cellular cytoplasmic proteins, neuwiedase was incubated with an homogenate of muscle cell proteins extracted from gastrocnemius muscles. This homogenate showed four main bands, corresponding to proteins with approximate molecular weights of 150,000 (band 1); 45,000 (2); 25,000 (3) and 18,000 (4) (Figure 3). According to the molecular sizes described in the literature, band 1 can be correlated to myosin heavy chain, band 2 to actin, band 3 to myosin light chain 1 , and band 4 to myosin light chain 2 (15). Hydrolysis of all major bands could be observed at early periods after neuwiedase incubation. However, at six hours, a drastic reduction of myosin corresponding bands (band 1, 3 and 4) was observed while band 2 was only slightly reduced. A total hydrolysis of the major bands of muscle proteins and appearance of many hydrolysis products was observed after 24 hours (Figure 3). These data suggest that neuwiedase is able to hydrolyze cytoplasmic proteins of muscle cells, being more selective initially for myosin. 


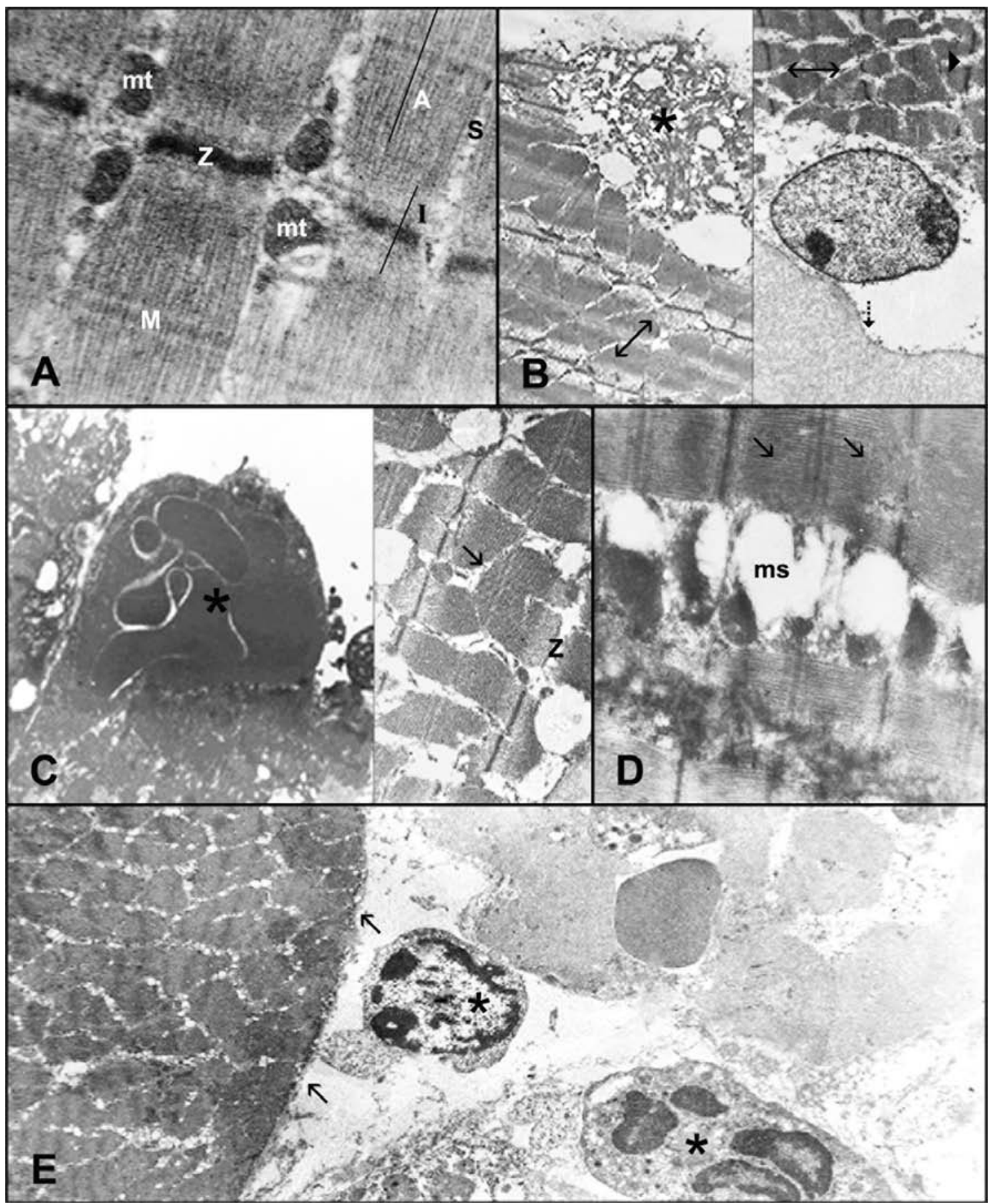

Figure 1. Ultrastructural alterations induced by neuwiedase in gastrocnemius muscle. (A) Control muscle inoculated with $50 \mu \mathrm{L}$ of PBS showing the integrity of the tissue. The sarcoplasm is filled with myofibrils and some mitochondria (mt). Sarcomeres show sarcoplasmic reticulum $(S)$ surrounding by $Z$ line $(Z)$, A bands (A) and I bands (I). The middle of the sarcomere is marked by the $\mathrm{M}$ line (M) situated within a lighter $\mathrm{H}$ band (magnification - 29,670x). (B) One hour after neuwiedase injection. Left, myofibril with lesion (asterisk). Right, $\mathrm{Z}$ line is discontinuous in some parts (arrowhead) and the plasma membrane appears interrupted (dotted arrow). Note the disorganization of the sarcomeres (double headed arrow) (magnification - left: 18,000x; right: 29,670x). (C) Three hours after neuwiedase injection. Left, inflammatory cell (asterisk) around the damaged tissue. Right, myofibril disruption (arrow) and $Z$ line interruption ( $Z$ ) (magnification - left: $50,000 x$, right: 85,836x). (D) Six hours after neuwiedase injection. Note the hypercontraction of myofilaments (arrows) and mitochondrial swelling (ms) (magnification - 20,000x). (E) Twenty-four hours after neuwiedase injection. Peripheral portion of the muscle fiber. Note the loss of integrity of the basal lamina and plasma membrane (arrows) and inflammatory cells around the damaged site (asterisks) (magnification - 29,670x). 


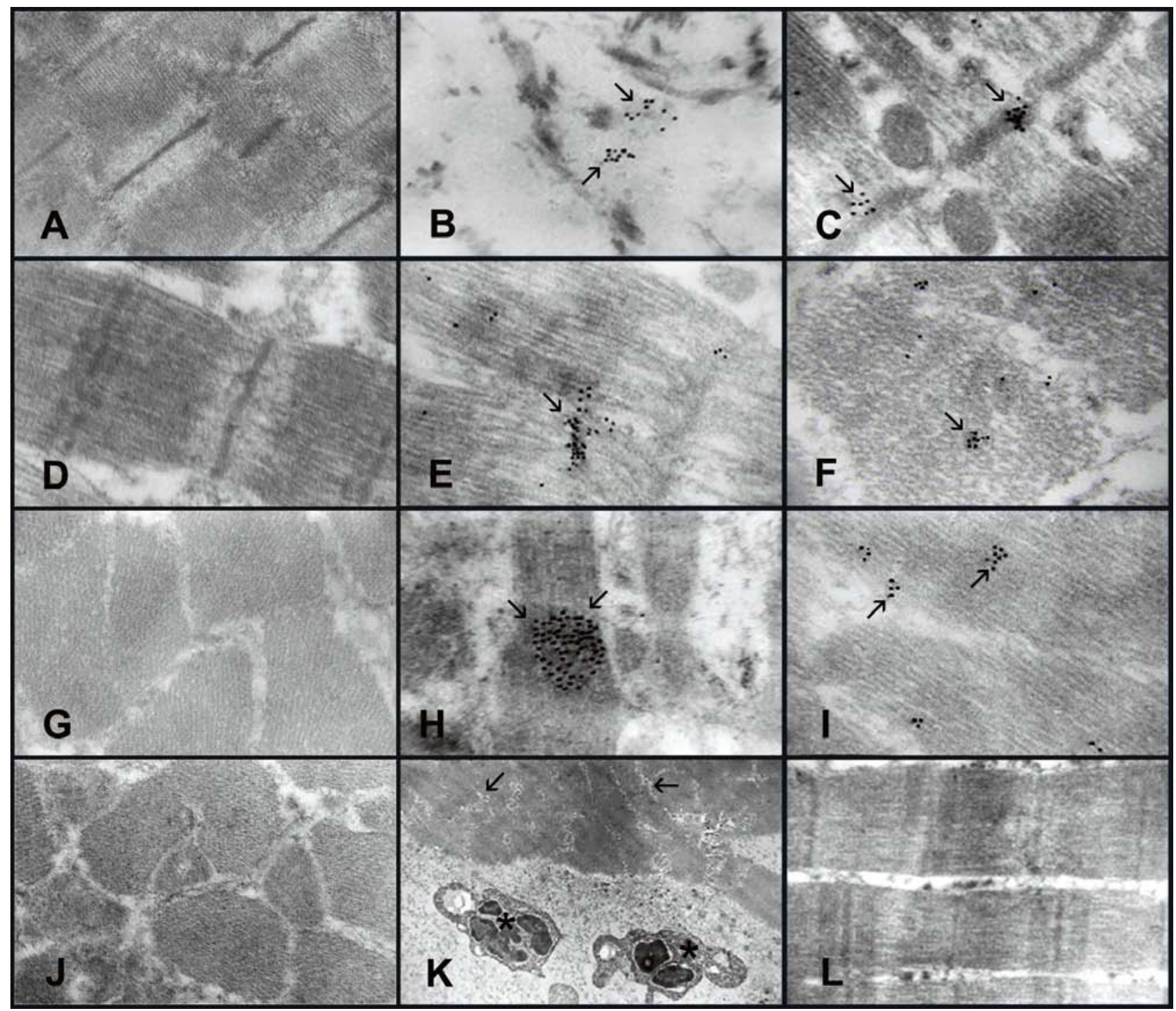

Figure 2. Immunodetection of neuwiedase on skeletal muscle tissue. (A) Fifteen minutes after PBS injection (magnification - 30,000x). (B, C) Fifteen minutes after neuwiedase injection (magnification - 85,000x): (B) immunopositive reaction (arrows) in the connective tissue and (arrows, C) specific labeling in $Z$ line. (D) Thirty minutes after PBS injection (magnification - 40,000x). (E, F) Thirty minutes after neuwiedase injection (magnification - 85,000x): (arrows, E) labeling in the I-band and (arrows, F) labeling among filaments. (G) One hour after PBS injection (magnification - 40,000x). (H, I) One hour after neuwiedase injection (magnification - 85,000x): immunopositive reaction at the A-band (arrows). (J) Three hours after PBS injection (magnification - 40,000x). (K) Three hours after neuwiedase injection (magnification 45,000x): mitochondrial swelling in the myofibrils (arrows) and inflammatory cells $\left({ }^{*}\right)$. (L) Control reaction with irrelevant antibody (rabbit anti-Toxoplasma gondii) (magnification - 52,000x). 


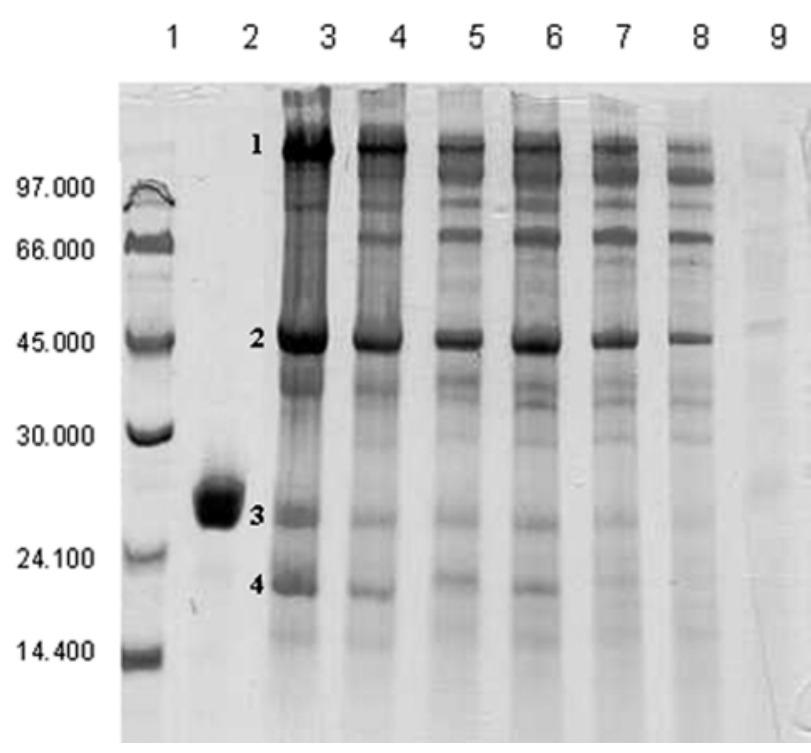

Figure 3. Proteolysis of muscle proteins induced by neuwiedase. Line 1: MW markers (GE Healthcare, USA): phosphorylase b $(97,000)$, albumin $(66,000)$, ovalbumin $(45,000)$, carbonic anhydrase $(30,000)$, trypsin inhibitor $(24,100)$, a-lactoalbumin $(14,400)$. Line 2: neuwiedase $(5 \mu \mathrm{g})$. Line 3: control myofibrils incubated with PBS for 24 hours. Lines 4-9: myofibrils incubated with neuwiedase for 5,30 and 60 minutes, and 3, 6, and 24 hours, respectively.

\section{DISCUSSION}

Skeletal muscle has been extensively used as a model to understand the pathological alterations induced by isolated snake venom toxins. In general, the action of these toxins on muscle fibers can be classified under direct or indirect action. The myonecrosis by direct action is caused by myotoxic phopholipases $A_{2}$, which affect the integrity of skeletal muscle cell plasma membranes, causing rapid hypercontraction and clumping of myofilaments (16). Indirect myonecrosis is generally associated with hemorrhagic SVMPs, inducing muscle damage via ischemia that develops secondary to their disruptive action on the vasculature (17).

Skeletal muscle fibers are multinucleated cells, composed of large numbers of parallel running myofibrils. The myofibrils, in turn, consist of overlapping and parallel thin actin filaments and thick myosin filaments. The functional unit of the muscle fibers is the sarcomere, which is delimited by two very dark colored bands called $\mathrm{Z}$ lines. The area between the $\mathrm{Z}$ lines is further divided into two lighter colored bands at either end called the I-bands, consisting primarily of actin, and a darker, grayish band in the middle called the A- band, composed primarily of myosin (18). Myosin is a major structural component of skeletal muscle and is considered to be the molecular motor that converts free energy derived from the hydrolysis of ATP into mechanical work. The appropriate expression of myosin in skeletal muscle is critical to the cell motor function (19).

The pathological alterations induced by neuwiedase on gastrocnemius muscle have been previously described (9). After intramuscular injection, neuwiedase induced a myotoxic effect (as evidenced histologically) as well as an increase in plasma creatine kinase levels. Since this toxin is devoid of hemorrhagic action and thrombotic effects, such myonecrosis could not be attributed as secondary to ischemic conditions induced by hemorrhage or thrombus formation, as often described for other SVMPs.

In order to understand the myotoxic effect induced by neuwiedase, the damage induced by this toxin on gastrocnemius muscle was analyzed by transmission electronic microscopy. After neuwiedase injection, skeletal muscle showed conspicuous damage of muscle fibers without any evidence of hemorrhage. This effect is characterized by alterations of cell plasma membrane and mitochondrial swelling, characteristic features of cell death (20). In addition, disruption of the basement membrane, which surrounds each muscle fiber, was also observed. This structure is composed of type IV collagen, laminin, nidogen/entactin and perlecan, and provides support and regulation of cell behavior (21). Thus, the degradation of these components, essential for muscle cell maintenance, could result in disarrangement of muscle fibers induced by neuwiedase. Following this argument, it was reported that neuwiedase was able to degrade extracellular matrix components such as laminin, type I collagen and fibronectin (8).

It is also important to consider that SVMPs are efficient in inducing over-expression of MMPs $(22,23)$. According to our previous study, neuwiedase induced the expression of proinflammatory MMP-9. However, the MMP-9 seemed to be more related to the inflammatory 
reaction than to the muscle damage induced by neuwiedase (10). In addition, the expression of MMP-9 was detected only after six hours of injection, when the muscle lesion induced by neuwiedase had already been installed.

An event never reported previously in the SVMPs literature was observed when tissues injected with neuwiedase were analyzed by immunocytochemistry. Highly specific labeling was detected in specific myofibril components of damaged muscle cells. At earlier time points (15 minutes post-injection), the positive reaction for neuwiedase was detected in the endomysium, a layer of connective tissue that surrounds each muscle cell, suggesting that the first step for cell damage may be the degradation of extracellular components, following by proteolysis of myofibrillar components.

Moreover, the degradation of myofibrillar components by neuwiedase, especially myosin, was also observed. It is important to point out that cell movement, muscular contraction, cytokinesis, membrane trafficking and signal transduction are driven by myosins that move unidirectionally along actin filaments (24). Thus, the degradation of myosin and other muscle proteins induced by neuwiedase could profoundly interfere with muscle cell function.

The results showed in this work suggest that neuwiedase probably induces myonecrosis by direct action. Direct myotoxicity was already described for other SVMPs from class P-I. LH-II, a P-I SVMP isolated from Lachesis muta muta, induced muscle damage one hour after injection in areas where hemorrhage was absent, also suggesting direct action on skeletal muscle cells (25). Furthermore, some metalloproteinases such as toxin $b$ from Crotalus atrox and bilitoxin from Agkistrodon bilineatus also induced direct myotoxicity (26, 27).

In summary, these results show that the cell muscle damage induced by neuwiedase may be related to proteolytic action on myofibrils and extracellular matrix components and these events are probably involved with the myotoxicity induced by this toxin. This is a newly reported mechanism possibly involved in the direct local tissue damage induced by SVMPs. Additional experiments are in progress in order to further understand the mechanisms of neuwiedase-induced myotoxicity.

\section{COPYRIGHT}

(C) CEVAP 2010

\section{SUBMISSION STATUS}

Received: January 21, 2010.

Accepted: April 22, 2010.

Abstract published online: June 6, 2010.

Full paper published online: August 31, 2010.

\section{CONFLICTS OF INTEREST}

There is no conflict.

\section{FINANCIAL SOURCE}

The National Council for Scientific and Technological Development (CNPq), Brazil, and The State of Minas Gerais Research Foundation (FAPEMIG), Brazil, provided the financial grants.

\section{ETHICS COMMITTEE APPROVAL}

The present study was approved by the Ethics Committee on Animal Experiments of Federal University of Uberlândia.

\section{CORRESPONDENCE TO}

CRISTIANI BALDO, Laboratório de Imunopatologia, Instituto Butantan, Av. Vital Brasil, 1500, São Paulo, SP, 05.503-900, Brasil. Phone: +55 1137267222 ext. 2087. Fax: +55 11 3726 1505. Email: cristianibaldo@butantan.gov. br.

\section{REFERENCES}

1. Gutiérrez JM, Lomonte B, Léon G, Rucavado A, Chaves F, Angulo Y. Trends in snakebite envenomation therapy: scientific, technological and public health considerations. Curr Pharm Des. 2007;13(28):2935-50.

2. Moura-da-Silva AM, Butera D, Tanjoni I. Importance of snake venom metalloproteinases in cell biology: effects on platelets, inflammatory and endothelial cells. Curr Pharm Des. 2007;13(28):2893-905.

3. Gutiérrez JM, Rucavado A, Escalante T, Díaz C. Hemorrhage induced by snake venom metalloproteinases: biochemical and biophysical mechanisms involved in microvessel damage. Toxicon. 2005;45(8):997-1011.

4. De Moraes CK, Fritzen M, Chudzinski-Tavassi AM, Selistre-de-Araújo HS. rACLF, a recombinant snake venom metalloprotease, activates endothelial cells in vitro. J Venom Anim Toxins incl Trop Dis. 2008;14(1):113-27.

5. Bode W, Gomis-Ruth FX, Stocker W. Astacins, 
serralysins, snake venom and matrix metalloproteinases exhibit identical zinc-binding environments (HEXXHXXGXXH and metturn) and topologies and should be grouped into a common family, the 'metzincins'. FEBS Lett. 1993;311(1-2):134-40.

6. Stocker W, Bode W. Structural features of a superfamily of zinc-endopeptidases: the metzincins. Curr Opin Struct Biol. 1995;5(3):38390.

7. Fox JW, Serrano SM. Insights into and speculations about snake venom metalloproteinase (SVMP) synthesis, folding and disulfide bond formation and their contribution to venom complexity. FEBS J. 2008;275(12):3016-30.

8. Rodrigues VM, Soares AM, Guerra-Sá R, Rodrigues V, Fontes MR, Giglio JR. Structural and functional characterization of neuwiedase, a nonhemorrhagic fibrin(ogen)olytic metalloprotease from Bothrops neuwiedi snake venom. Arch Biochem Biophys. 2000;381(2):213-24.

9. Rodrigues VM, Soares AM, Andrião-Escarso SH, Franceschi AM, Rucavado A, Gutiérrez JM, et al. Pathological alterations induced by neuwiedase, a metalloproteinase isolated from Bothrops neuwiedi snake venom. Biochimie. 2001;83(6):471-9.

10. Lopes DS, Baldo C, Oliveira Cde F, de Alcântara TM, Oliveira JD, Goulart LR, et al. Characterization of inflammatory reaction induced by neuwiedase, a P-I metalloproteinase isolated from Bothrops neuwiedi venom. Toxicon. 2009;54(1):42-9.

11. De Haas GH, Postema NM, Nieuwenhuizen W, van Deenen LL. Purification and properties of phospholipase A from porcine pancreas. Biochim Biophys Acta. 1968;159(1):103-17.

12. Geesink GH, Morton JD, Kent MP, Bickerstaffe R. Partial purification and characterization of Chinook salmon (Oncorhynchus tshawytscha) calpains and an evaluation of their role in postmortem proteolysis. J Food Science. 2000;65(8): 1318-24.

13. Bradford MM. A rapid and sensitive method for the quantification of microgram quantities of protein utilizing the principle of protein-dye binding. Anal Biochem. 1976;72(1):248-54.

14. Laemmli UK. Cleavage of structural proteins during the assembly of the head of bacteriophage T4. Nature. 1970;227(5259):680-5.

15. Gutiérrez JM, Arce V, Brenes F, Chaves F. Changes in myofibrillar components after skeletal muscle necrosis induced by a myotoxin isolated from the venom of the snake Bothrops asper. Exp Mol Pathol. 1990;52(1):25-36.
16. Gutiérrez JM, Lomonte B. Phospholipase $A_{2}$ myotoxins from Bothrops snake venoms. Toxicon. 1995;33(11):1405-24.

17. Gutiérrez JM, Rucavado A. Snake venom metalloproteinases: their role in the pathogenesis of local tissue damage. Biochimie. 2000;82(910):841-50.

18. Bach AD, Beier JP, Stern-Staeter J, Horch RE. Skeletal muscle tissue engineering. J Cell Mol Med. 2004;8(4):413-22.

19. Schiaffino S, Reggiani C. Molecular diversity of myofibrillar proteins: gene regulation and functional significance. Physiol Rev. 1996;76 (2):371-423

20. Moreira L, Borkow G, Ovadia M, Gutiérrez JM. Pathological changes induced by $\mathrm{BaH} 1$, a hemorrhagic proteinase isolated from Bothrops asper (terciopelo) snake venom, on mouse capillary blood vessels. Toxicon. 1994;32(8):97787.

21. LeBleu VS, Macdonald B, Kalluri R. Structure and function of basement membranes. Exp Biol Med. 2007;232(9):1121-9.

22. Rucavado A, Nunez J, Gutierrez JM. Blister formation and skin induced by BaP1, a haemorrhagic metalloproteinase from the venom of the snake Bothrops asper. Int J Exp Pathol. 1998;79(4):245-54.

23. Rucavado A, Escalante T, Teixeira CFP, Fernandes CM, Diaz C, Gutiérrez JM. Increments in cytokines and matrix metalloproteinases in skeletal muscle after injection of tissue-damaging toxins from the venom of the snake Bothrops asper. Mediators Inflamm. 2002;11(2):121-8.

24. Warrick HM, Spudich JA. Myosin structure and function in cell motility. Annu Rev Cell Biol. 1987;3(1):379-421.

25. Rucavado A, Flores-Sanchez E, Franceschi A, Magalhães A, Gutiérrez JM. Characterization of the local tissue damage induced by LHF-II, a metalloproteinase with weak hemorrhagic activity isolated from Lachesis muta muta snake venom. Toxicon. 1999;37(9):1297-312.

26. Ownby CL, Bjarnason J, Tu AT. Hemorrhagic toxins from rattlesnake (Crotalus atrox) venom. Pathogenesis of hemorrhage induced by three purified toxins. Am J Pathol. 1978;93(1):201-18.

27. Ownby CL, Nika T, Imai $K$, Sugihara $H$. Pathogenesis of hemorrhage induced by bilitoxin, a hemorrhagic toxin isolated from the venom of the common cantil (Agkistrodon bilineatus bilineatus). Toxicon. 1990;28(7):837-46. 